\title{
Cardiac CT in an aberrant right coronary artery
}

\author{
Jan Menke
}

Institute for Diagnostic and Interventional Radiology, University Medical Center Göttingen, Göttingen, Germany

\section{Correspondence to}

Dr Jan Menke,

Menke-J@T-Online.de

Accepted 3 February 2015

\section{DESCRIPTION}

An 18-year-old man experienced acute chest pain. Transthoracic echocardiography was normal. ECG showed anterior ST-depression and posterior ST-elevation, and the troponin-T test was positive. Therefore the differential diagnosis included a myocardial ischaemic event. Catheter angiography ruled out coronary artery disease but detected an anomalous origin of the right coronary artery at the upper left sinus of Valsalva. Contrast-enhanced cardiac CT was subsequently performed (figure 1), with panel A (plus video 1) showing an angulated transverse reformation and panel B (plus video 2) a coronal reformation. The CT depicted a high interarterial course of the aberrant right coronary artery (figure 1 , arrows) with acute take-off angle $\left(20^{\circ}\right)$ and slit-like compression between the aortic root (figure 1, "1") and pulmonary trunk (figure 1, "2"). The length of the stenotic segment was about $13 \mathrm{~mm}$. Its minimum vessel area was $2.8 \mathrm{~mm}^{2}$, corresponding to an area with stenosis of $70 \%{ }^{1}$ Such malignant coronary artery variants can have an increased risk of cardiac events and sudden cardiac death. ${ }^{1-3}$ The patient opted for coronary artery bypass grafting from the right internal thoracic artery to the right coronary artery and has been well since then.

The clinical decision of bypass surgery versus conservative therapy depends on individual factors, including whether the coronary artery variant is

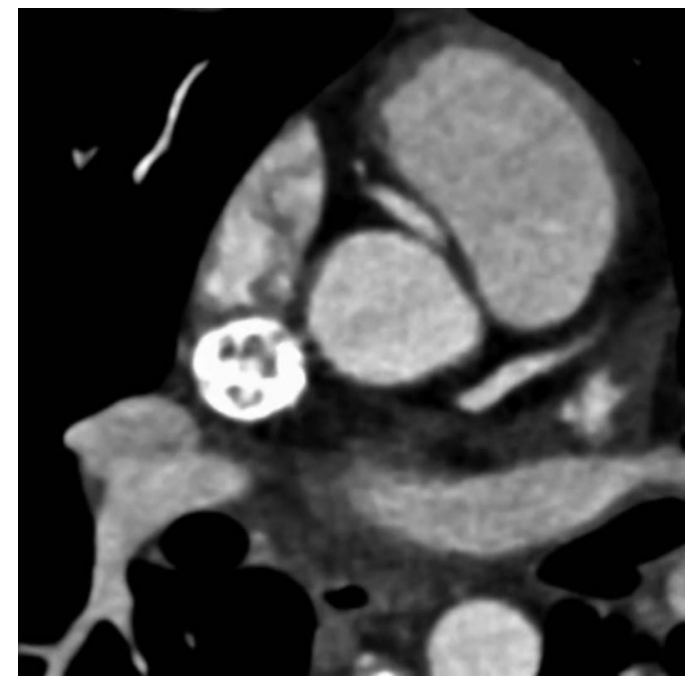

Video 1 Cardiac CT, transverse plane. Please compare to figure 1 (A). This video shows the course of the proximal right coronary artery in cranial-to-caudal direction. Further details are provided in the text.

incidentally detected in an asymptomatic patient or whether it is symptomatic. In this young man it was symptomatic and bypass grafting was performed to prevent further cardiac events. The CT was valuable for confirming the coronary artery anomaly at high image resolution three-dimensionally. ${ }^{1-3}$

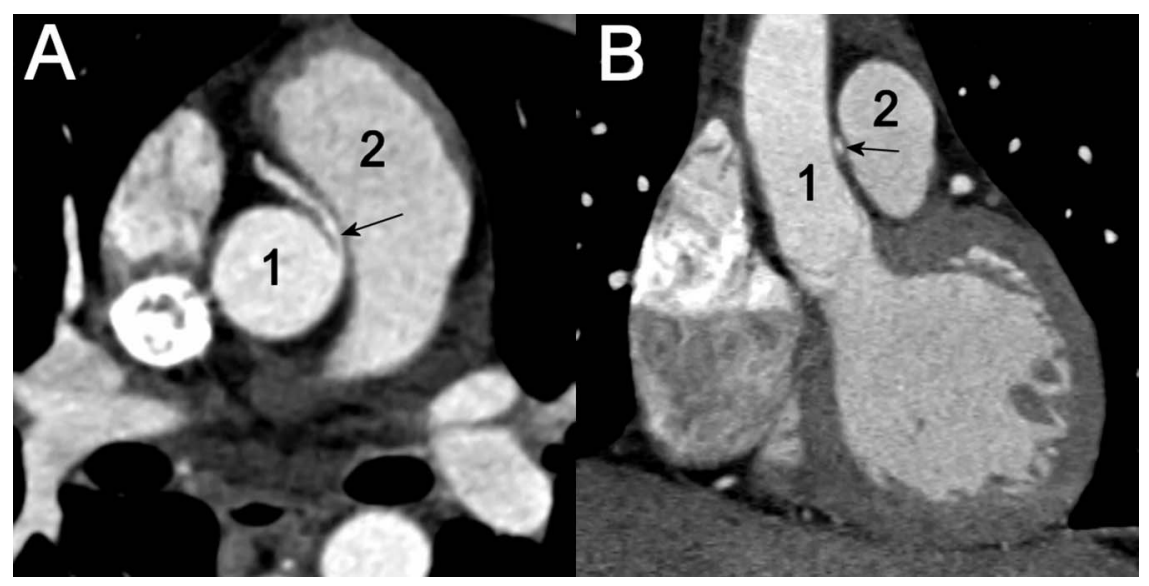

Figure 1 Cardiac CT showing (A) an angulated transverse reformation and (B) a coronal reformation. The right coronary artery (arrow) has an interarterial course between the aortic root (1) and the pulmonary trunk (2). Further details are provided in the text. 


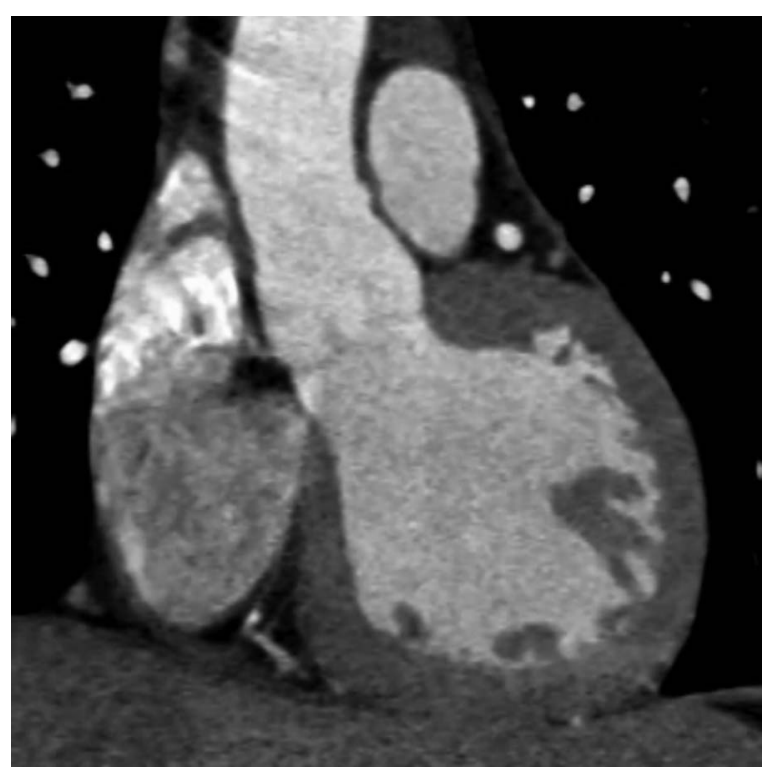

Video 2 Cardiac CT, coronal reformation. Please compare to figure 1 (B). This video shows the course of the proximal right coronary artery in posterior-to-anterior direction. Further details are provided in the text.

\section{Learning points}

- Cardiac CT is suitable for showing aberrant coronary arteries.

- An interarterial course of the right coronary artery belongs to the so-called 'malignant' variants that can have an increased risk of cardiac events and sudden cardiac death.

- The clinical decision between surgical versus conservative therapy depends on individual factors, such as the patient's symptoms.

\section{Competing interests None.}

Patient consent Obtained.

Provenance and peer review Not commissioned; externally peer reviewed.

\section{REFERENCES}

1 Ashrafpoor G, Danchin N, Houyel L, et al. Anatomical criteria of malignancy by computed tomography angiography in patients with anomalous coronary arteries with an interarterial course. Eur Radiol 2015;25:760-6.

2 Lee HJ, Hong YJ, Kim HY, et al. Anomalous origin of the right coronary artery from the left coronary sinus with an interarterial course: subtypes and clinical importance. Radiology 2012;262:101-8.

3 Krupinski M, Urbanczyk-Zawadzka M, Laskowicz B, et al. Anomalous origin of the coronary artery from the wrong coronary sinus evaluated with computed tomography: "High-risk" anatomy and its clinical relevance. Eur Radiol 2014;24:2353-9.

Copyright 2015 BMJ Publishing Group. All rights reserved. For permission to reuse any of this content visit http://group.bmj.com/group/rights-licensing/permissions.

BMJ Case Report Fellows may re-use this article for personal use and teaching without any further permission.

Become a Fellow of BMJ Case Reports today and you can:

- Submit as many cases as you like

- Enjoy fast sympathetic peer review and rapid publication of accepted articles

- Access all the published articles

- Re-use any of the published material for personal use and teaching without further permission

For information on Institutional Fellowships contact consortiasales@bmjgroup.com

Visit casereports.bmj.com for more articles like this and to become a Fellow 